\title{
Malnutrition and infection: an update
}

\author{
Noel W. Solomons* \\ CeSSIAM, Guatemala City, Guatemala
}

The original Scrimshaw, Taylor and Gordon conceptual framework for the interaction of nutrition and infection has well served the scientific community for almost half a century. At its core is the notion of synergistic (mutually reinforcing) and antagonistic (mutually nullifying) influences of the malnourished state on infectious conditions and vice versa. Research on a series of advancing fronts, however, has allowed the incorporation of both relevant public health issues (parasitosis, emerging infectious diseases, obesity and overweight, etc.) and advancing science (molecular immunology, oxidation biology, multiple micronutrient deficiencies, etc.). The present review is an interpretative update on close to 50 years of demographic and epidemiological evolution in the field of human nutrition and the implications for the interaction in the context of microbiological and immunological developments on the infectious side of the dialectic.

Infection: Malnutrition: Micronutrients: Immune modification

\section{The interaction of malnutrition and infection}

The literature review and critical analysis by Nevin Scrimshaw, Carl Taylor and John Gordon in the treatise Interaction of Nutrition and Infection, first published as a review article in $1959^{1}$ and then as a World Health Organization monograph in $1968^{2}$, set out a paradigm which has endured for almost a half century.

Demographics, food supply and epidemiological transitions determine the specific relevance of the malnutrition-infection interaction in individual circumstances. Until the advent of the AIDS pandemic, average life-expectancies were rising everywhere in the world; this was largely as a consequence of a reduction in early deaths from infectious childhood diseases. Today, it is in only one region of the world, Africa, where infectious disease is the leading cause of mortality. With receding infectious mortality and increasing age, chronic non-communicable diseases have become the leading causes of death everywhere else. With a rise in life-expectancy over the years since the publication by Scrimshaw et $a l^{1}$, the world's population has grown to over 6 billion persons, such that the absolute number of potentially lethal infectious episodes remains the same, or continues to rise ${ }^{3}$.

Rates of severe protein-energy malnutrition have declined over the decades as food supplies have generally kept pace with population growth and distribution has improved. If agricultural technology cannot continue to keep up with the rising food demand, however, there could be a reversal of the current downward trend in macronutrient deficiency states ${ }^{4}$. The populations living in cities and experiencing rising affluence, moreover, are the most likely to have access to a calorie-sufficient diet, and to change their selection of foods and beverages away from the national traditions. Such nutrition transition ${ }^{5}$ generally leads to an increase in consumption of animal fat and protein, with a reduction in the contribution of complex carbohydrates and a reciprocal increase in refined sugar intakes.

The purpose of this review is to provide an update for the first decade of the third millennium on the biological science and the public health relevance of the paradigm of the interaction of malnutrition and infection, in the face of dynamic and evolving changes in diet and infectious disease patterns and risks.

\section{Micronutrients and disease resistance}

International research has provided many insights in recent years on the therapeutic and prophylactic effects and efficacy of micronutrient fortification or supplementation on infectious disease resistance.

Micronutrients as an adjuvant to the mitigation of infections:

On the therapeutic side, extensive research and meta-analysis largely confirms a survival advantage and reduction in morbidity for complicated measles in hospitalised children with high-dose vitamin A supplementation ${ }^{6-8}$. Similarly, supplementation with oral zinc in diarrhoea, treated with oral rehydration therapy, reduces the duration and severity of episodes, and has been officially recommended by the WHO $^{9}$.

\section{Micronutrients in the prevention of infections:}

Ensuring adequate micronutrient status is important for the prevention of certain infections. Although vitamin A has been termed the "anti-infective nutrient," there is little evidence that it prevents the incidence of new infections ${ }^{10,11}$. 
It is more likely that the effect of vitamin A supplementation on preventing death from childhood disease ${ }^{12,13}$ is one of reducing the severity of infectious illnesses. The one area in which this vitamin has actually been strongly suggested to prevent infections is in small premature infants ${ }^{14}$.

Similarly, although iron supports components of the host defence system such as phagocytosis, there is no evidence of it preventing infections ${ }^{15,16}$. In contrast, zinc is emerging as a nutrient whose supplementation can reduce the risk of infections ${ }^{17}$ and re-infection ${ }^{18}$. Vitamin D and infection is a recently emerging area of interest with promise for prophylactic application in epidemic viral diseases such as influenza and diverse microbial infections ${ }^{19,20}$.

\section{Broadening the focus on human pathogens and malnutrition}

One of the important features of the past five decades has been the emergence of new infectious agents important to the overarching nutrition-infection paradigm which were not considered in detail by Scrimshaw et $a l^{2}$. This is true for parasites, because their importance to human health was not fully appreciated five decades ago. It is also true for the human immunodeficiency virus (HIV), which had not yet appeared, and for a series of other pathogens which have only since been emerging, or re-emerging, as causes of human infection.

\section{Malnutrition, protozoa and multicellular parasites:}

One classical scenario of pathogens depleting nutritional stores of the host is the blood loss caused by intestinal hookworms. The biology of protozoa and multicellular parasites is much more complex than that of viruses or bacteria, having a more intricate interaction with host nutritional status. The influence of human nutritional status on the success of parasitic infection has intrigued investigators $^{21}$. One particular such example is the interaction of host vitamin A status and certain filarial nematodes which have evolved elaborated retinoid receptor systems to access the vitamin $\mathrm{A}$ of their host ${ }^{22}$.

\section{Human immunodeficiency virus:}

The HIV/AIDS pandemic began with the discovery of the syndrome in 1981. A large body of experience from experimental micronutrient interventions, aimed at potentially enhancing immune function, viral counts and disease outcomes in mothers and their offspring, is available for review ${ }^{23}$. One paradoxical finding stands out: except for infants, in which vitamin A supplementation can be lifesaving, high-dose vitamin A often has adverse consequences for HIV. On the other hand, a multi-micronutrient supplement has produced benefits in mothers and infants ${ }^{23}$. The effect of Vitamin D on $\mathrm{HIV}^{24}$ is currently under inquiry, based on a series of theoretical considerations.

With the advent of AIDS, we observe that, in addition to the physiological, the social aspects of the infection can be detrimental to an individual's nutritional well being. The social stigma surrounding AIDS, as well as the loss of working and earning capacity, compromises the food security of the household, contributing further to nutritional deficiencies ${ }^{25,26}$. In retrospect, a similar social dynamic of marginalisation undoubtedly occurred with other infections of chronic evolution, such as leprosy and the white plague (tuberculosis) in the past, but they were not recognised in the infection-malnutrition context.

\section{Other emerging infectious diseases:}

AIDS is considered an emerging infectious disease, having only been recognised in 1981. It is, however, not alone in this category of diseases which have emerged, often by zoonotic transmission, to the human population. Table 1 provides a list of selected organisms or infectious syndromes in the emerging category for which virtually nothing is known of the nutritional influences - synergistic, antagonistic or nil which offer opportunities for new discoveries of potential public health importance. Among the reasons for the emergence of new human pathogens are: migration and changing demographics, rapid international travel, microbial adaptations, altered land use and human behaviour ${ }^{27}$.

\section{Overnutrition and infection}

The term "malnutrition" in the era of Scrimshaw et $a l^{2}$ was virtually synonymous with undernutrition. This was before the emergence of the nutrition transition ${ }^{5}$. As argued by Uauy and Solomons ${ }^{28}$, today we need to insist upon a broader and more comprehensive definition of malnutrition. In other words, one that spans the entire spectrum of deviant nutritional status, from short stature and below normal weight to

Table 1. A non-exhaustive listing of infectious agents and conditions in the domain of emerging and re-emerging infectious diseases

\begin{tabular}{l}
\hline Organisms \\
Avian influenza H5N1 virus \\
Bartonella \\
Coxiella \\
Ebola virus \\
Ehrlichia \\
Enteroaggregative Escherichia coli \\
Enterohaemorrhagic Escherichia coli \\
Gymnophalloides seoi (trematode) \\
Hanta virus \\
Human immunodeficiency virus (HIV) \\
Nipah virus \\
Nontuberculous Mycobacteria \\
Norovirus (Norwalk agent) \\
Metapneumovirus \\
Monkey pox \\
Penicillium marneffei \\
Polyomaviruses \\
Saccharomyces cerevisiae \\
Toscana virus \\
Infectious conditions \\
Babesiosis \\
Coccidioidomycosis \\
Melioidosis \\
Mucormycosis \\
Microsporidiosis \\
Relapsing fever \\
Rickettsioses \\
Severe acute respiratory syndrome (SARS) \\
Tularemia \\
Variant Creutzfeldt-Jakob disease (mad cow) \\
West Nile viral encephalitis \\
Zygomycosis \\
\end{tabular}


the various grades of overweight and obesity. Indeed, sometime after the dawn of the new millennium, the number of persons worldwide classified as over-nourished, based on the criteria of the body mass index, became equal to those classified as undernourished, based on weight-for-age criteria ${ }^{29}$.

Comparative reviews of body composition patterns in developing countries have shown the dual-burden of nutrition, with persisting sectors of the population in undernourished states while growing segments develop overnutrition ${ }^{30,31}$. The underlying dynamics that have turned the traditional risk of being underweight to one of being overweight and obese in developing countries have recently been detailed $^{32-34}$. To the extent that problems of overweight continue to increase worldwide, these considerations will become even more important for infectious risk.

\section{Overweight and infectious disease risk:}

As far back as 25 years ago it occurred to Edelman ${ }^{35}$ to ask the question of whether obesity modulates infectious disease and immunity. It is surprising how few investigative responses this call received. In the realm of common consensus, it is suggested that obese individuals are more susceptible to infection than lean subjects. For reasons related to the anatomical distortions of overweight, clinical wisdom accepts as a fact that obese individuals have greater risk of bacteremia and a prolonged wound healing time after surgical operations. There is documentation that the fatty liver of obesity may also favour persistence of the hepatitis $\mathrm{C}$ virus ${ }^{36}$. In addition, obesity increases the incidence of cutaneous infections of interest to the dermatology community; including candidiasis, intertrigo, furunculosis, erythrasma, tinea cruris, and folliculitis. Less common infections include cellulitis, necrotising fascitis, and gas gangrene ${ }^{37}$.

\section{Antagonistic interactions of iron status and infection:}

Weinberg $^{38}$ has coined the term "nutritional immunity" to denote the situation in which the deficiency of a nutrient might provide protective advantage to the host by restricting the access to a nutrient required for the proliferation of a specific pathogen. The most common example of an antagonistic interaction arises in the context of iron excess and overload states. In 1949, Elsdon-Dew ${ }^{39}$ noted that fulminant amoebiasis was selective to certain ethnic groups in South Africa, namely Bantu males who have an excess of iron due to consumption of an iron-laden brew. Diamond et al ${ }^{40}$ provided a mechanistic context for this phenomenon by showing in an animal model (the hamster) that the iron status of the animal conditions the systemic virulence of Entamoeba histolytica. In further experimental work, Beck et $a l^{41}$ showed that a normally benign murine coxsackie virus damages heart muscle in vitamin E-deficient mice when overloaded with iron. In related clinical observations in pediatric patients, Brocks et $a l^{42}$ documented an increased risk of gram negative sepsis with parenteral injection of iron dextran supplements.

Malaria has taken centre stage in the contemporary consideration of the antagonistic effects of iron and plasmodial infections. Pregnant women taking iron-containing prenatal supplements in Plasmodium vivax-endemic areas have increased susceptibility to malarial attacks. More dramatically, a major field intervention trial on the island of Pemba in Zanzibar, Tanzania, an area holo-endemic for the more lethal Plasmodium falciparum, was suspended. In-study monitoring revealed adverse effects such as increased hospitalisation and excess mortality in children under 36 months of age who had been randomised to receive $12.5 \mathrm{mg}$ of iron daily, along with $50 \mu \mathrm{g}$ of folic acid ${ }^{44}$.

\section{The immune system connection to nutrients and nutrition}

The most expansive evolution over the 4 decades of research has been the progressive accumulation of knowledge about the inner workings of the host immune system, from the biology of the cellular and humoral responses to the current peeling away of the molecular secrets. This progress in fundamental immunobiology has not been ignored by the nutritional community ${ }^{45,46}$.

\section{Molecular biology of the immune system:}

The examples of discoveries concerning the role of the immune host defence at the molecular biology levels are too numerous and complex to summarise here. The insights began to emerge when immunologists with an interest in nutrition adopted and adapted the emerging tools of molecular biology. A case in point involving zinc is the work performed in Pamela Fraker's laboratory ${ }^{47}$ in the late $1990 \mathrm{~s}$. She and her colleagues suggested the effects on lymphocyte glucocorticoid receptors from zinc restriction in laboratory rodents as a mechanism for immunosuppression. Emerging from the same era was the work of Melinda Beck and coworkers $^{48}$, which showed in a mouse model that the pulmonary damage due to an influenza virus is greater in a selenium deficient animal. At the molecular and cellular basis, the lack of oxidative protection led to an increased oxidative response, which directly spurred on the local inflammation.

\section{Nutrients, nutritional status and immunisations:}

It has been considered whether simultaneous delivery of vitamin A and key immunisations (e.g. measles, polio) has any influence of the efficacy of the latter. The consensus was that no interference occurred $^{49}$. More recently, a similar question of nutrientvaccination interactions has been raised with respect to zinc and a cholera vaccine. Studies in Bangladesh have shown that seroconversion and production of antibodies after an oral cholera vaccine were improved after zinc supplementation, whereas high-dose vitamin A had no enhancing effect ${ }^{50}$.

\section{Manipulation of the immune response:}

The manipulation of the immune response takes on a number of creative formats. It has been speculated that early hunter-gatherers' penchant for grazing on the roots of foraged plants introduced anaerobic microbes that protected evolutionary man from infections. The contemporary equivalent of this is the attempts to take advantage of probiotics (live anaerobic fermentation bacteria) to treat or prevent infectious human and animal diseases. This has been explored most with regard to gastrointestinal infections ${ }^{51}$. Meta-analyses of published trials indicate the 
effectiveness of prophylactic use of probiotics to prevent traveler's diarrhoea ${ }^{52}$ and to avert antibiotic-associated infections with Clostridium dificile $e^{53}$. When a more comprehensive view of all the explored applications is taken, diverse efficacy trials have provided more mixed results ${ }^{54}$.

The earliest mammalian milk (colostrum) contains an abundance of immune factors. Since all of the passive immunity for ruminant newborns is passed on through the colostrum, the efficacy of bovine colostrum for treating and preventing human infections has been of clinical and public health interest. Reviews of the topic show that bovine colostrum immunoglobulins survive the passage through the human gastrointestinal tract intact and can have both therapeutic and prophylactic effects against selected pathogens ${ }^{55,56}$.

A bold gambit for immunology has been therapeutic application of biological response modifiers, notably anti-cytokine therapy $^{57}$. Dampening down the systemic effects of the acute-phase response by antibodies to suppress inflammatory cytokines was pioneered in the treatment of inflammatory rheumatoid conditions ${ }^{58}$. Its application to systemic inflammation caused by infectious pathogens is the next frontier ${ }^{59}$.

\section{Newer paradigms on the research horizon}

As this narrative of concept development and basic and applied research in the area of infection and nutrition points out, there has been a continuous ebb and flow of shifting paradigms. One related to dietary pattern and another related to host nutritional status.

\section{Dietary pattern for infections disease resistance:}

To what extent the dietary pattern, per se, influences the risk of illness was first explored in the $1980 \mathrm{~s}$ in the U.S. National Research Council report Diet and Health ${ }^{60}$. Since then, dietary guidelines for long-term health and prevention of chronic disease have evolved. For the U.S. population, these are currently set out in MyPyramid ${ }^{61}$.

The paradigm of an interaction between food, diet and acute disease has been explored to a much lesser extent. However, in the instance of infant feeding, a strong association between the exclusive or predominant consumption of maternal milk and protection from infections in the infant and toddler years has been documented ${ }^{62,63}$.

Some interesting observations of diet-infection associations in somewhat older children (preschoolers) came from a field study in Tanzania ${ }^{64,65}$. This was part of a vitamin A supplementation intervention, which failed to reveal any benefit in morbidity or mortality. However, the total intake of vitamin A from the diet was protective against childhood infections. Insofar as total dietary vitamin A in rural Tanzania may be a proxy measure for consumption of carotene-rich foods, e.g. herbs, vegetables and pigmented fruits, the disease resistance observed may be attributable to constituents of these pigmented foods.

\section{Pathogen virulence and the nutritional status of the host:}

Keshan disease was a progressive and fatal pulmonary disease in East Asia, which was found to be associated with low selenium status in the population ${ }^{66}$. Beck et $a l^{67}$ looked at murine models of pulmonary infections using a usually benign mouse coxsackie virus which produced a self-limited, mild respiratory infection in well-nourished mice. The same virus, however, turned virulent when selenium deficient mice were inoculated; the mutated virus isolated from the selenium-restricted host was also now lethal when passed into selenium-sufficient animals. This observation points towards a new departure in nutrition:infection interactions - where the micronutrient status of the host could determine the virulence of pathogens across a whole society ${ }^{68}$.

\section{Conclusion}

Scrimshaw, Taylor and Gordon ${ }^{1,2}$ enunciated a paradigm for interactions of nutrition and infection that continues to serve both biological science and public health. The fact that half of all continuing infectious deaths are associated with a low weight-for-age ${ }^{69}$ is compelling testimony to the enduring relevance of the paradigm. Half a century of explosive population growth, scientific expansion in immunology and molecular biology, changing population demography, and evolving infectious and nutritional epidemiology places the interaction of nutrition and infection into a myriad of new and relevant contexts.

\section{Conflict of interest statement}

The author has no conflicts of interest to report.

\section{References}

1. Scrimshaw NS, Taylor CE \& Gordon JE (1959) Interaction of nutrition and infection. Am J Med Sci 237, 367-403.

2. Scrimshaw NS, Taylor CE \& Gordon JE (1968) Interaction of nutrition and Infection. Technical Monograph Series No. 57. Geneva: World Health Organization.

3. Glass RI, Lew JF, Gangarosa RE, LeBaron CW \& Ho MS (1991) Estimates of morbidity and mortality rates for diarrheal diseases in American children. J Pediatr 118, S27-S33.

4. Rosegrant MW \& Cline SA (2003) Global food security: challenges and policies. Science 302, 1917-1919.

5. Drewnowski A \& Popkin BM (1997) The nutrition transition: new trends in the global diet. Nutr Rev 5, 31-43.

6. Hussey GD \& Klein M (1990) A randomized, controlled trial of vitamin A in children with severe measles. $N$ Engl J Med 323, $160-164$.

7. Coutsoudis A, Broughton M \& Coovadia HM (1991) Vitamin A supplementation reduces measles morbidity in young African children: a randomized, placebo-controlled, double-blind trial. Am J Clin Nutr 54, 890-895.

8. Huiming Y, Chaomin W \& Meng M (2005) Vitamin A for treating measles in children. Cochrane Database Syst Rev 4, CD001479.

9. World Health Organization/UNICEF joint statement (2004), Clinical management of Acute Diarrhoea. New York, NY, and Geneva, Switzerland:, The United Nations Children's Fund/ World Health Organization, pp. 1-8. New York: UNICEF.

10. Underwood BA (1994) Was the "anti-infective" vitamin misnamed? Nutr Rev 52, 140-143.

11. Semba RD (1999) Vitamin A as "anti-infective" therapy, 19201940. J Nutr 129, 783-791. 
12. Sommer A, Tarwotjo I, Hussaini G \& Susanto D (1983) Increased mortality in children with mild vitamin A deficiency. Lancet 2, 585-588.

13. Sommer A, Tarwotjo I, Djunaedi E, West KP Jr, Loeden AA, Tilden R \& Mele L (1986) Impact of vitamin A supplementation on childhood mortality. A randomised controlled community trial. Lancet 1, 1169-1173.

14. Darlow BA \& Graham PJ (2002) Vitamin A supplementation for preventing morbidity and mortality in very low birthweight infants. Cochrane Database Syst Rev 4, CD000501.

15. Iannotti LL, Tielsch JM, Black MM \& Black RE (2006) Iron supplementation in early childhood: health benefits and risks. Am J Clin Nutr 84, 1261-1276.

16. Gera T \& Sachdev HP (2002) Effect of iron supplementation on incidence of infectious illness in children: systematic review. BMJ 325, 1142.

17. Roy SK, Tomkins AM, Haider R, Behren RH, Akramuzzaman SM, Mahalanabis D \& Fuchs GJ (1999) Impact of zinc supplementation on subsequent growth and morbidity in Bangladeshi children with acute diarrhoea. Eur J Clin Nutr 53, 529-534.

18. Baqui AH, Black RE, El Arifeen S, Yunus M, Chakraborty J, Ahmed S \& Vaughan JP (2002) Effect of zinc supplementation started during diarrhoea on morbidity and mortality in Bangladeshi children: community randomised trial. BMJ 325, 1059.

19. Tremezaygues L, Sticherling M, Pfohler C, et al. (2006) Cutaneous photosynthesis of vitamin D: an evolutionary highly-conserved endocrine system that protects against environmental hazards including UV-radiation and microbial infections. Anticancer Res 26, 2743-2748.

20. Cannell JJ, Vieth R, Umhau JC, et al. (2006) Epidemic influenza and vitamin D. Epidemiol Infect 134, 1129-1140.

21. Solomons NW \& Keusch GT (1981) Nutritional implications of parasitic infections. Nutr Rev 39, 149-161.

22. Sani BP \& Comley JC (1985) Role of retinoids and their binding proteins in filarial parasites and host tissues. Trop Med Parasitol 36, Suppl 1, 20-23.

23. Mehta S, Finkelstein JL \& Fawzi W (2007) Nutritional interventions in HIV-infected breastfeeding women. Annales Nestlé [English] 65, 9-28.

24. Villamor E (2006) A potential role for vitamin D on HIV infection? Nutr Rev 64, 226-233.

25. Gillespie S, Haddad L \& Jackson R (2001) Food and nutrition security: Impacts and actions. Nutrition and HIV/AIDS. Nutrition Policy Paper No. 20. SCN News 31-45.

26. Solomons NW \& O'Donnell GE (2007) HIV and the ramifications for food security and child health in affected communities. Annales Nestlé [English] 65, 9-28.

27. Leiby DA (2005) Emerging infectious agents. Dev Biol (Basel) 120, $11-15$.

28. Uauy R \& Solomons NW (2006) The role of the international community in addressing the dual burden of malnutrition with a common agenda. SCN News 32, 27-34.

29. Mendez MA, Monteiro CA \& Popkin BM (2005) Overweight exceeds underweight among women in most developing countries. Am J Clin Nutr 81, 714-721.

30. de Onis M \& Blossner M (2000) Prevalence and trends of overweight among preschool children in developing countries. Am J Clin Nutr 72, 1032-1039.

31. Martorell R, Khan LK, Hughes ML \& Grummer-Strawn LM (2000) Obesity in women from developing countries. Eur J Clin Nutr 54, 247-252.

32. Bourne LT, Lambert EV \& Steyn K (2002) Where does the black population of South Africa stand on the nutrition transition? Public Health Nutr 5, 157-162.

33. Siervo M, Grey P, Nyan OA \& Prentice AM (2006) Urbanization and obesity in The Gambia: a country in the early stages of the demographic transition. Eur J Clin Nutr 60, $455-463$.

34. Gracey MS (2007) Nutrition-related disorders in Indigenous Australians: how things have changed. Med J Aust 186, 15-17.

35. Edelman R (1981) Obesity: does it modulate infectious disease and immunity? Prog Clin Biol Res 67, 327-337.

36. McCullough AJ (2003) Obesity and its nurturing effect on hepatitis C. Hepatology 38, 557-559.

37. Scheinfeld NS (2004) Obesity and dermatology. Clin Dermatol 22, 303-309.

38. Weinberg ED (1999) Iron withholding: A defense against viral infections. Biometals 9, 393-399.

39. Elsdon-Dew R (1949) Endemic fulminant amebic dysentery. Am J Trop Med Hyg 29, 337-340.

40. Diamond LS, Harlow DZ, Phillips BP \& Keister DB (1978) Entamoeba histolytica: iron and nutritional immunity. Archivos de Investigacion Medica (Mex) 9, Suppl. 1, 329-338.

41. Beck MA, Shi Q, Morris VC \& Levander OA (2005) Benign coxsackievirus damages heart muscle in iron-loaded vitamin E-deficient mice. Free Radic Biol Med 38, 112-116.

42. Brocks JH (1999) Benefits and dangers of iron during infection. Curr Opin Clin Nutr Metab Care 2, 507-510.

43. Nacher M, McGready R, Stepniewska K, Cho T, Looareesuwan S, White NJ \& Nosten F (2003) Haematinic treatment of anaemia increases the risk of Plasmodium vivax malaria in pregnancy. Trans $R$ Soc Trop Med Hyg 97, 273-276.

44. Sazawal S, Black RE, Ramsan M, et al. (2006) Effects of routine prophylactic supplementation with iron and folic acid on admission to hospital and mortality in preschool children in a high malaria transmission setting: community-based, randomised, placebo-controlled trial. Lancet 367, 133-143.

45. Scrimshaw NS \& SanGiovanni JP (1997) Synergism of nutrition, infection and immunity: an overview. Am J Clin Nutr 66, 464S-477S.

46. CunninghamRundles S, McNeeley DF \& Moon A (2005) Mechanisms of nutrient modulation of the immune response. J Allergy Clin Immunol 115, 11191128.

47. Fraker P (2000) Impact of nutritional status on immune integrity. In Nutrition and Immunity: Principles and practice, pp. 147-156 [ME Gershwin, JB German and CL Keen, editors]. Tokawa NJ: Humana Press.

48. Beck MA, Nelson HK, Shi Q, et al. (2001) Selenium deficiency increases the pathology of an influenza virus infection. FASEB J 15, 1481-1483.

49. Expanded Programme on Immunization (EPI) (1997) Safety and efficacy of measles vaccine/vitamin A supplementation. Wkly Epidemiol Rec 72, 329-331.

50. Albert MJ, Qadri F, Wahed MA, et al. (2003) Supplementation with zinc, but not vitamin A, improves seroconversion to vibriocidal antibody in children given an oral cholera vaccine. $J$ Infect Dis 187, 909-913.

51. Penner R, Fedorak RN \& Madsen KL (2005) Probiotics and nutraceuticals: non-medicinal treatments of gastrointestinal diseases. Curr Opin Pharmacol 5, 596-603.

52. McFarland LV (2007) Meta-analysis of probiotics for the prevention of traveler's diarrhea. Travel Med Infect Dis 5, 97-105.

53. Szajewska H, Ruszczynski M \& Radzikowski A (2006) Probiotics in the prevention of antibiotic-associated diarrhea in children: a meta-analysis of randomized controlled trials. J Pediatr 149, 367-372.

54. NASPGHAN Nutrition Report CommitteeMichail S, Sylvester F, Fuchs G \& Issenman R (2006) Clinical efficacy of probiotics: review of the evidence with focus on children. J Pediatr Gastroenterol Nutr 43, 550-557.

55. Lilius EM \& Marnila P (2001) The role of colostral antibodies in prevention of microbial infections. Curr Opin Infect Dis 14, 295-300. 
56. Solomons NW (2002) Modulation of the immune system and the response against pathogens with bovine colostrum concentrates. Eur J Clin Nutr 56, Suppl. 3, S24-S28.

57. Buchwald UK \& Pirofski L (2003) Immune therapy for infectious diseases at the dawn of the 21st century: the past, present and future role of antibody therapy, therapeutic vaccination and biological response modifiers. Curr Pharm Des 9, 945-968.

58. Hochberg MC, Lebwohl MG, Plevy SE, Hobbs KF \& Yocum DE (2005) The benefit/risk profile of TNFblocking agents: findings of a consensus panel. Semin Arthritis Rheum 34, , 819-836.

59. Dinarello CA (2003) Anti-cytokine therapeutics and infections. Vaccine 21, Suppl. 2, S24-S34.

60. National Research Council (1990) Diet and Health. Washington DC: National Academy of Sciences Press.

61. United States Department of Agriculture MyPyramid, http:// www.MyPyramid.gov

62. Villalpando S \& Hamosh M (1998) Early and late effects of breast-feeding: does breast-feeding really matter? Biol Neonate 74, 177-191.

63. World Health Organization (2000) Effect of breastfeeding on infant and child mortality due to infectious diseases in less developed countries: a pooled analysis. WHO Collaborative
Study Team on the Role of Breastfeeding on the Prevention of Child Mortality. Lancet 355, 451-455.

64. Fawzi WW, Herrera MG, Willett WC, Nestel P, el Amin A, Lipsitz S \& Mohamed KA (1994) Dietary vitamin A intake and the risk of mortality among children. Am J Clin Nutr 59, 401-408.

65. Fawzi WW, Herrera MG, Willett WC, Nestel P, el Amin A \& Mohamed KA (1995) Dietary vitamin A intake and the incidence of diarrhea and respiratory infection among Sudanese children. J Nutr 125, 1211-1221.

66. Jackson ML (1988) Selenium: geochemical distribution and associations with human heart and cancer death rates and longevity in China and the United States. Biol Trace Elem Res 15, 13-21.

67. Beck MA, Kolbeck PC, Shi Q, Rohr LH, Morris VC \& Levander OA (1994) Increased virulence of a human enterovirus (coxsackievirus B3) in selenium-deficient mice. J Infect Dis 170, 351-357.

68. Beck MA \& Levander OA (2000) Host nutritional status and its effect on a viral pathogen. J Infect Dis 182, Suppl 1, S93-S96.

69. Pelletier DL \& Frongillo EA (2003) Changes in child survival are strongly associated with changes in malnutrition in developing countries. J Nutr 133, 107-119. 